Psychological Medicine, 2003, 33, 1145-1148. (C) 2003 Cambridge University Press

DOI: $10.1017 / \mathrm{S} 0033291703008638$ Printed in the United Kingdom

\title{
EDITORIAL
}

\section{Life events: effects and genesis ${ }^{1}$}

It is more than 40 years since a burst of studies in the late 1960s started what has become a substantial corpus of work, establishing the role of life events in psychiatric disorders (Brown \& Birley, 1968; Paykel et al. 1969). Findings depended on advances in methodology. First, came development of a life events questionnaire and a scaling of their stress magnitude (Holmes \& Rahe, 1967); then, replacement by more reliable and valid interview methods and better ways of distinguishing major and minor events (Brown \& Harris, 1978; Paykel, 1996).

At the start the work met entrenched opposing views - from one side that the real causes of psychiatric disorder were all constitutional, genetic and biological; from the other side that they lay in deeper, psychodynamic conflicts, originating in infancy and childhood. These polarizations in psychiatry have now greatly lessened. The general body of life event findings has become widely accepted. Recent stressful life events precede episodes of a variety of psychiatric disorders, particularly suicide attempts, and depression (Paykel \& Cooper, 1992). The events are not very specific to disorders although there is some closer association with depression for events involving interpersonal loss, and those involving loss of self-esteem or humiliation. The effect is moderate in magnitude but varies with disorder - less in schizophrenia than depression, probably less in bipolar affective disorder than unipolar; within unipolar depression stronger in first episodes and milder disorders than in severe recurrent disorders. Effects are strongest near the onset of the disorder, and decay over time, with most of the effect occurring within 6 months to a year.

In this issue of Psychological Medicine we report six studies of life events. They use a variety of approaches to answer a number of questions.

Four papers, each using a different approach, involve depression, the disorder that has received most study. Rahman et al. (2003) extend to a rural community in Pakistan, questions regarding post-natal depression that have been examined in Western affluent populations. They find high prevalence of depression both 6 weeks before delivery and around 3 months post-natally, and strong associations with severe events and difficulties in the previous year. These findings are similar to those obtained in the Western world (Paykel et al. 1980; O'Hara, 1986). In this much more deprived population the events reported by women were also mainly similar, with marital and family problems looming large, although events involving economic hardships such as loss of job by the breadwinner and financial difficulties were also prominent, as might be expected.

This kind of life event case-control study has a long history and continues to appear. In another recent paper Brilman \& Ormel (2001) used a nested case-control design in a large community survey of elderly people, and found a strong effect for severe life events on depressive episodes, particularly first episodes. Rubenowitz et al. (2001) used a case-control approach with informant interview to show effects of familial problems and family discord on suicide. Maciejewski et al. (2001) in a community survey found women more likely than men to experience an episode of depression after a major event. However, such studies are now mainly replicatory.

Farmer \& McGuffin (2003), a distinguished husband and wife pair who have made notable contributions to psychiatric genetics, adopt a sib-pair approach to study issues arising directly from the work of George Brown on the qualities of events which are important. Siblings share some of both the social background and genetic load of the probands. Farmer \& McGuffin find depressives more likely to have experienced a severe threatening event, loss event or humiliation

\footnotetext{
${ }^{1}$ Address for correspondence: Professor E. S. Paykel, Department of Psychiatry, University of Cambridge, Douglas House, 18E Trumpington Road, Cambridge CB2 2AH.
} 
event, than their siblings or general population controls. Depressed men were more often exposed to humiliation events than depressed women. Could this have been a consequence of males tending to compete in work-related hierarchies? The authors also report some evidence that exposure to nonsevere events protect, perhaps by enhancing coping. Here replication is needed: the previous studies that have looked at non-severe events have found little effect, or a weak stress-additive effect.

In previous sib-pair work using this sample (Farmer et al. 2001 a) sensation-seeking questionnaire scores showed a familial element and were associated with more events of low threat, but were not associated with the higher threat events related to depression, and showed an inverse association with depression itself. In another analysis dysfunctional attitudes were only very weakly familial and were mainly determined by low mood (Farmer et al. 2001 b). In another sib-pair sample (Rijsdijk et al. 2001) this group found moderate familiality for network events, less for personal events. Adverse life events were associated with depression and anxiety.

Kessing et al. (2003) use a different approach, record linkage, to examine major events and first hospital admission for depression. The advantage is reliable event data not affected by patient or interviewer distortions. The disadvantage is that only a few, very major events, are recorded this way, and hospital admission is not the same as onset of disorder, and may have its own separate social influences. They find effects of divorce, recent unemployment, and suicide of first-degree relative, but not other deaths. The effect is constant over the adult lifespan.

These three studies of depression represent a tidying up of remaining questions and replications by different methods. Other life event approaches include more general epidemiological studies, used in recent years to study various social stress risk factors. Thus, aircraft noise was found by Haines et al. (2001) in a sample of school children to affect reading comprehension and noise annoyance, but not psychiatric symptoms. Absence of social support was found by Brugha et al. (2003) to be associated with type of adult neurotic symptoms, particularly depression. Impact of work related factors has been found to be greater in males than females and in working class rather than higher social class subjects (Matthews et al. 2001). Impact of job strain has also been reported on coronary heart disease (Sacker et al. 2001). Another approach is the prospective study of the specific event - a very good way of studying modifying factors. This approach is inherent in much of the modern literature on post traumatic stress disorder, and the kind of events which precede it (Emmelkamp et al. 2002).

Hatcher \& House (2003) tackle a newer area where the degree of psychological aetiology is still argued: chronic fatigue syndrome. They use the Bedford College Interview and a classical retrospective case-control design. Their subjects with chronic fatigue syndrome were more likely than general population controls to have experienced severe events and difficulties in the 3 months before onset, with a high odds ratio, and a smaller effect over 1 year. These authors also report a new class of event, a dilemma, which strongly distinguishes subjects and controls. The idea derives from concepts of conflict in conversion disorder. It needs more study in other disorders, to determine if there is specificity.

Kendler et al. (2003a) report in this issue a further study in an important series exploring a rich vein - what causes a life event? Clearly life events are not always simply external random occurrences: we all, by earlier life decisions, social-setting and lifestyle, influence the life events from which we suffer.

One element in this is genetic (Plomin et al. 1990). Kendler and colleagues have made productive use of twin studies. They used the large Virginia twin registry, and first obtained postal questionnaire reports of occurrence of 44 life events in the past year (Kendler et al. 1993). Correlations were a little higher in monozygotic twins than dizygotic. Genetic and common environmental elements each accounted for about $20 \%$ of the variance, with the former predominant in 'network' events affecting individuals in the respondent's social networks, and the latter higher for 'personal' events directly affecting the respondent. In later waves, information was collected by interview. Genetic elements affected liability to develop depression after life events (Kendler et al. 1995). Genetic liability to major depression increased the risk of being exposed to life events, mainly personal ones, outside the depressive episode (Kendler \& Karkowski-Shuman, 1997). Alcoholism increased risk of 
being robbed and having trouble with the law. About one-third of the relationship between life events and depression appeared to be non-causal, due to self-selection into high risk environments (Kendler et al. 1999a). In a further paper (Kendler et al. 1999b), no evidence was found for genetic effects on independent events of personal or network classes, but the latter showed considerable effects of familial environment. Dependent events showed genetic effects. Recently this group have also found genetic elements in social support (Agrawal et al. 2002). They have also used discordant twin pairs to study recent life events and early stress factors unique to the individual and not reflecting genetic factors or family of origin effects (Kendler \& Gardner, 2001).

In the current paper (Kendler et al. 2003a), they examine the association between the personality traits of neuroticism and both stressful life events and the quality of interpersonal relationships. They had previously confirmed the heritability of neuroticism (Kendler et al. 2003 b). They now report a complex analysis using earlier reports by twins of neuroticsm, and later reported life events and interpersonal dimensions from a social interaction measure. They find neuroticism to predict occurrence of most life events and all interpersonal dimensions. This is not due to reporting bias as it also applies to neuroticism in the subjects as reported by the co-twin.

In the sixth paper in this issue, which returns to depression, Patton et al. (2003) use a different approach to what is cause and what is consequence by studying the occurrence of life events and of depression over two waves in an epidemiological community study of adolescents. They find previous depression and anxiety to predict later events, and events in turn to predict later depression, even without previous symptoms.

In earlier work on related issues, Champion et al. (1995) found that children who had shown emotional or behavioural disturbance aged 10, when studied in their late 20s had markedly higher rates in the 5 years before the follow-up interview of highly threatening events and difficulties, both dependent and independent. Van Os \& Jones (1999), using a longitudinal birth cohort, found that stressful life events in midlife were predicted by high neuroticism in childhood. This measure also predicted stronger effects of life events on disorder.

An emerging area of major importance concerns mechanisms - how do life events induce disorder? In a recent unusual study Myin-Germeys et al. (2003) found evidence that major life events produced their effects on patients with remitted psychotic illness by increasing emotional reactivity to minor daily stresses. Does this indicate a biological, brain mediated effect? In the long run, the effects of stress on psychiatric symptoms and disorder must be through the brain, and brain-social stress interactions are ripe for study, in animals and humans. Interactions with early disease processes, personal characteristics such as gender and personality, equally require further study.

We have achieved the recognition that causative sequences are complex, and should not be viewed in simple black or white terms of environment or genes, social stress or brain and other biology. Both are intertwined. There will be more of this research in the future as the causative chains, the interactions between their elements and the mechanisms are more fully elucidated.

\section{REFERENCES}

Agrawal, A., Jacobson, K. C., Prescott, C. A. \& Kendler, K. S. (2002). A twin study of sex differences in social support. Psychological Medicine 32, 1155-1164.

Brilman, E. I. \& Ormel, J. (2001). Life events, difficulties and onset of depressive episodes in later life. Psychological Medicine 31, 859-869.

Brown, G. W. \& Birley, J. L. T. (1968). Crises and life changes and the onset of schizophrenia. Journal of Health and Social Behaviour 9, 203-214.

Brown, G. W. \& Harris, T. O. (1978). Social Origins of Depression: A Study of Psychiatric Disorder in Women. Tavistock: London.

Brugha, T. S., Morgan, Z., Bebbington, P., Jenkins, R., Lewis, G., Farrell, M. \& Meltzer, H. (2003). Social support networks and type of neurotic symptom among adults in British households. Psychological Medicine 33, 307-318.

Champion, L. A., Goodall, G. \& Rutter, M. (1995). Behavioural problems in childhood and stressors in early adult life 1 . A 20 year follow-up of London school children. Psychological Medicine 25, 231-246.

Emmelkamp, J., Komproe, H. H., van Ommeren, M. \& Schagen, S. (2002). The relation between coping, social support and psychological and somatic symptoms among torture survivors in Nepal. Psychological Medicine 32, 1465-1469.

Farmer, A. \& McGuffin, P. (2003). Humiliation, loss and other types of life events and difficulties: a comparison of depressed subjects, healthy controls and their siblings. Psychological Medicine 33, 1169-1175.

Farmer, A., Redman, K., Harris, T., Mahmood, A., Sadler, S. \& McGuffin, P. (2001a). Sensation-seeking, life events and 
depression: the Cardiff Depression Study. British Journal of Psychiatry 178, 549-552.

Farmer, A., Harris, T., Redman, K., Mahmood, A., Sadler, S. \& McGuffin, P. (2001b). The Cardiff Depression Study: a sib-pair study of dysfunctional attitudes in depressed probands and healthy control subjects. Psychological Medicine 31, 627-633.

Haines, M. M., Stansfeld, S. A., Job, R. F. S., Berglund, B. \& Head, J. (2001). Chronic aircraft noise exposure, stress responses, mental health and cognitive performance in school children. Psychological Medicine 31, 265-278.

Hatcher, S. \& House, A. (2003). Life events, difficulties and dilemmas in the onset of chronic fatigue syndrome: a case-control study. Psychological Medicine 33, 1185-1192.

Holmes, T. H. \& Rahe, R. H. (1967). The Social Readjustment Rating Scale. Journal of Psychosomatic Research 11, 213-318.

Kendler, K. S. \& Gardner, C. O. (2001). Monozygotic twins discordant for major depression: a preliminary exploration of the role of environmental experiences in the aetiology and course of illness. Psychological Medicine 31, 411-424.

Kendler, K. S., Neale, M., Kessler, R., Heath, A. \& Eaves, L. (1993). A twin study of recent life events and difficulties. Archives of General Psychiatry 50, 789-796.

Kendler, K. S., Kessler, R. C., Walters, E. E., MacLean, C., Neale, M. C., Heath, A. C. \& Eaves, L. J. (1995). Stressful life events, genetic liability, and onset of an episode of major depression in women. American Journal of Psychiatry 152, 833-842.

Kendler, K. S. \& Karkowski-Shuman, L. (1997). Stressful life events and genetic liability to major depression: genetic control of exposure to the environment? Psychological Medicine 27, 539-547.

Kendler, K. S., Karkowski, L. M. \& Prescott, C. A. (1999a). Causal relationship between stressful life events and the onset of major depression. American Journal of Psychiatry 156, 837-841.

Kendler, K. S., Karkowski, L. M. \& Prescott, C. A. (1999b). The assessment of dependence in the study of stressful life events: validation using a twin design. Psychological Medicine 29, $1455-1460$.

Kendler, K. S., Gardner, C. O. \& Prescott, C. A. (2003a). Personality and the experience of environmental adversity. Psychological Medicine 33, 1193-1202.

Kendler, K. S., Aggen, S. H., Jacobson, K. C. \& Neale, M. C. $(2003 \mathrm{~b})$. Does the level of family dysfunction moderate the impact of genetic factors on the personality trait of neuroticism? Psychological Medicine 33, 817-825.

Kessing, L. V., Agerbo, E. \& Mortensen, P. B. (2003). Does the impact of major stressful life events on the risk of developing depression change throughout life? Psychological Medicine 33, $1177-1184$.
Maciejewski, P. K., Prigerson, H. G. \& Mazure, C. M. (2001). Sex differences in event-related risk for major depression. Psychological Medicine 31, 593-604.

Matthews, S., Power, C. \& Stansfeld, S. A. (2001). Psychological distress and work and home roles: a focus on socio-economic differences in distress. Psychological Medicine 31, 725-736.

Myin-Germeys, I., Krabbendam, L., Delespaul, P. A. E. G. \& Van Os, J. (2003). Do life events have their effect on psychosis by influencing the emotional reactivity to daily life stress: Psychological Medicine 33, 327-334.

O'Hara, M. W. (1986). Social support, life events, and depression during pregnancy and the puerperium. Archives of General Psychiatry 43, 569-573.

Patton, G. C., Coffey, C., Posterino, M. \& Carlin, J. B. (2003). Life events and early onset depression: cause or consequence? Psychological Medicine 33, 1203-1210.

Paykel, E. S. (1996). The Interview for Recent Life Events. Psychological Medicine 27, 301-310.

Paykel, E. S. \& Cooper, Z. (1992). Life events and social stress. In Handbook of Affective Disorders: 2nd edn. (ed. E. S. Paykel), pp. 149-170. Churchill Livingstone: Edinburgh.

Paykel, E. S., Myers, J. K., Dienelt, M., Klerman, G. L., Lindenthal, J. \& Pepper, M. (1969). Life events and depression: a controlled study. Archives of General Psychiatry 21, 753-760.

Paykel, E. S., Emms, E. M., Fletcher, J. \& Rassaby, E. S. (1980). Life events and social support in puerperal depression. British Journal of Psychiatry 136, 339-346.

Plomin, R., Lichtenstein, P., Pedersen, N., McClearn, G. E. \& Nesselroade, J. R. (1990). Genetic influences on life events during the last half of the life span. Psychology of Aging 5, 25-30.

Rahman, A., Iqbal, Z. \& Harrington, R. (2003). Life events, social support and depression in child birth: perspectives from a rural community in the developing world. Psychological Medicine 33, 1161-1167.

Rijsdijk, F. V., Sham, P. C., Sterne, A., Purcell, S., Cherny, S. S., Webster, M., Ball, D., Eley, T. C. \& Plomin, R. (2001). Life events and depression in a community sample of siblings. Psychological Medicine 31, 401-410.

Rubenowitz, E., Waern, M., Wilhelmson, K. \& Allebeck, P. (2001). Life events and psychosocial factors in elderly suicides-a case-control study. Psychological Medicine 31, 1193-1202.

Sacker, A., Bartley, M. J., Frith, D., Fitzpatrick, R. M. \& Marmot, M. G. (2001). The relationship between job strain and coronary heart disease: evidence from an English sample of the working male population. Psychological Medicine 31, 279-290.

Van Os, J. \& Jones, P. B. (1999). Early risk factors and adult personenvironment relationships in affective disorder. Psychological Medicine 29, 1055-1067. 